\title{
Erratum to: Computational structural analysis of proteins of Mycobacterium tuberculosis and a resource for identifying off-targets
}

\author{
Sameer Hassan • Abhimita Debnath • \\ Vasantha Mahalingam • Luke Elizabeth Hanna
}

Published online: 5 July 2012

(C) Springer-Verlag 2012

\section{Erratum to: J Mol Model}

DOI 10.1007/s00894-012-1412-5

The original version of this article unfortunately contained a mistake. On page 3 , line 15 - the sentence "The $\mathrm{R}^{2}$ statistic can range from -1 to 1 , with 1 representing perfect positive correlation and -1 representing perfect negative correlation" should be corrected to "The values of $\mathrm{R}$ squared range from 0 to 1 and the $\mathrm{R}$ correlation can range from -1 to 1 , with 1 representing perfect positive correlation and -1 representing perfect negative correlation".

The online version of the original article can be found at http://dx.doi.org/ 10.1007/s00894-012-1412-5.

S. Hassan · A. Debnath • L. E. Hanna $(\bowtie)$

Department of Biomedical Informatics,

National Institute for Research in Tuberculosis,

Chetpet, Chennai, India

e-mail: hanna@trcchennai.in

\section{Mahalingam}

Department of Statistics,

National Institute for Research in Tuberculosis,

Chetpet, Chennai, India

L. E. Hanna

Department of Clinical Research,

National Institute for Research in Tuberculosis,

Chetpet, Chennai 600031, India 